\title{
Exposure to maternal odor enhances intake of a taste that mimicks the sensory attributes of ethanol
}

\author{
María C. Ifran ${ }^{1,2} \cdot$ Andrea B. Suárez $^{3} \cdot$ Andrea N. Loarte $^{1,2} \cdot$ Ricardo M. Pautassi $^{3} \cdot$ Giselle V. Kamenetzky $^{1,2}$ \\ Published online: 1 July 2019 \\ (C) The Psychonomic Society, Inc. 2019
}

\begin{abstract}
Early exposure to ethanol increases subsequent acceptance of this drug. Little attention, however, has been devoted to the interaction of the taste of the drug with other, familiar or non-familiar, odors contingent with ethanol access, particularly early in ontogeny. This study assessed the influence of exposure to maternal odor on intake and grasp responses to an artificial nipple providing a solution (a sucrose-quinine mix) that emulates the taste of alcohol, in 4-day-old rat pups. The results showed that the mother's odor enhanced intake from and seeking responses to an artificial nipple that provided the solution that mimicked the taste of alcohol (Experiment 1). This pattern of results was not evoked by the odor of an unrelated dam (Experiment 2), nor was it observed when the nipple delivered water. The main new finding of the present study is that 4-day-old rats tested in the presence of the mother (and hence exposed to her odor cues) exhibited enhanced seeking and intake of a solution that mimics the chemosensory properties of ethanol.
\end{abstract}

Keywords Odor $\cdot$ Taste $\cdot$ Ontogeny $\cdot$ Rats

\section{Introduction}

The roots of alcohol-use problems (i.e., alcohol abuse and dependence) can be traced to very early stages in life (Molina, Spear, Spear, Mennella, \& Lewis, 2007). Human fetuses or babies can be involuntarily exposed to alcohol through different cultural practices, e.g., through breast milk or amniotic fluid, after maternal intoxication with the drug. Epidemiological and preclinical research indicates that these early experiences significantly modulate subsequent voluntary alcohol drinking (March, Abate, Spear, \& Molina, 2009).

María C. Ifran

celeste.ifran@gmail.com

1 Instituto de Investigaciones Médicas A Lanari, IDIM-CONICET, Universidad de Buenos Aires, Combatientes de Malvinas 3150, CP 1427 Buenos Aires, Argentina

2 Centro de Altos Estudios en Ciencias Humanas y de la Salud (CAECIHS-UAI), Universidad Abierta Interamericana, Buenos Aires, Argentina

3 Instituto de Investigaciones Médicas M. y M. Ferreyra (INIMEC-CONICET-Universidad Nacional de Córdoba), Friuli 2434, CP 5000 Córdoba, Argentina
In the not too distant past (Mennella \& Beauchamp, 1993a), it was considered that drinking small quantities of alcohol before nursing increased milk yield, facilitated milk let-down, or induced relaxation of the mother-baby dyad. Abundant evidence, however, indicates that drinking before nursing disrupts lactation performance and alters infant behavior and development (Mennella \& Gerrish, 1998; Zeanah, Boris, \& Larrieu, 1997). Furthermore, ethanol alters the flavor of breast milk, a change that results in an altered suckling behavior pattern. Mennella and Beauchamp (1991a; also see Mennella, 1999) observed that babies whose mothers consumed alcohol before nursing, compared to babies whose mothers had not consumed alcohol, performed more suckling during the first minute of the meal, yet they consumed significantly less milk by the end of the observation.

These studies (Mennella \& Beauchamp, 1991a; Mennella, 1999) inferred that ethanol changed the flavor of the milk or induced sedation or activation. The influence of the maternal odor in the context of suckling, and the possibility of this odor promoting or coming into association with ethanol intake or exposure, has not, however, been considered.

The present study employed an animal (rat) model in which tastes and odors interact in the context of suckling for a substance (a quinine-sucrose compound) that emulates the taste of 
alcohol. Preweanling and neonate rats detect and discriminate between flavors, even when taste buds are not fully developed (Ganchrow, Steiner, \& Canetto, 1986; Nizhnikov, Petrov, Varlinskaya, \& Spear, 2002). In preweanling rats, familiarization with the odor of ethanol (Bannoura, Kraebel, Spear, \& Spear, 1998) or with ethanol's unconditional effects (Arias \& Chotro, 2005a; Diaz-Cenzano \& Chotro 2010; Kiefer \& Lawrence, 1988) results in (1) a greater preference for ethanol's odor and (2) a greater intake of either ethanol or a sucrose-quinine mix, which mimics the psychophysical properties of ethanol (Kiefer, Bice, Orr, \& Dopp, 1990; López \& Molina, 1999).

Olfactory stimuli are critical during the early stages of life in the development of mammals. Altricial species learn behaviors that facilitate approach towards the caregiver (Moriceau \& Sullivan 2005). The maternal odor changes depending on diet, and rat pups are born without fully developed visual and auditory systems. Such flexibility in odor learning allows pups to find the nest and maternal nipple through smell (Pedersen, Williams, \& Blass, 1982). This species exhibits a sensitive period, which lasts about 10 days from the time of birth, in which odor preexposure results in long-lasting learned preferences (Moriceau, Roth, Okotoghaide, \& Sullivan, 2004; Upton \& Sullivan, 2010). Such olfactory learning continues repeatedly throughout the early postnatal period, which presumably allows the infant to adjust to changes in the mother's odor (Landers \& Sullivan, 2012). The relevance of this age-specific predisposition declines as subjects undergo transition into adolescence and adulthood. Previous data from our lab indicated that stimulation with a familiar, pre-exposed odor (i.e., lemon scent) either during gestational or postnatal life, increased seeking and intake of quinine (an aversive solution; Berridge, 2000) in neonate rats tested via an artificial nipple (Kamenetzky, Suárez, Pautassi, Mustaca, \& Niznikov, 2015; Kamenetzky, Suárez, Ifran, Nizhnikov, \& Pautassi, 2018). Furthermore, other studies from our laboratory showed that the presence of maternal odor also increased these ingestive behaviors toward a surrogate nipple at postnatal day (PD) 4 (Ifran, Suárez, Pautassi, \& Kamenetezky, 2018). This suggested that familiar odors can switch the hedonic value of aversive solutions in rats, and reproduced results of greater acceptance of unpalatable flavors seen in studies with human babies. During the first 4 months of life, human infants exhibit a sensitive period in flavor programming, characterized by an enhanced predisposition to accept unpalatable flavors. Protein hydrolysate formulas (which are bitter and have a rancid smell) are accepted before 4 months of age, yet strongly rejected by older infants and children (Beauchamp \& Mennella, 2011; Mennella \& Beauchamp, 1996). The mechanisms of this flavor programming in infancy and the action of both senses (smell and taste) working jointly during early ontogeny have not been widely explored.

The present study assessed seeking and drinking of a mixed solution (quinine + sucrose) that mimics the taste of ethanol. Prior research has used this solution to study the responsivity to ethanol's sensory properties without the confounding factor of ethanol's pharmacological (e.g., motor-activating or depressing) effects (Bachmanov et al., 2003; López \& Molina, 1999), and the influence of the maternal odor in the testing situation. The hypothesis of our study was that stimulation with a pre-exposed, biologically relevant odor (i.e., mother's odor), would enhance seeking (i.e., grasping of the nipple) and drinking of a solution that mimics the taste of alcohol. Fourday-old rats were given access to a nipple providing sucrose+ quinine, either with or without the anesthetized mother. A second experiment replicated the procedure but added further controls (i.e., animals stimulated with the odor of another, unrelated mother and animals given only water at test). At the age studied rats discriminate between different tastes, and even more noteworthy, they adjust the intake behavior depending on taste offered (e.g., sweet, bitter) and on the different concentrations of the solutions (Kamenetzky et al., 2015; Miller \& Spear, 2008, 2009, 2010). Consistent with this factor, researchers found that 3-hour-old pups regulate intake behavior according to the taste and the nutritional value of food (Nizhnikov, Petrov, Varlinskaya, \& Spear, 2002; Petrov, Nizhnikov, Kozlov, Varlinskaya, Kramskaya, \& Spear, 2004).

This current investigation provides valuable information on understanding how the olfactory and gustatory systems work in unison during early life and how this interaction can influence alcohol intake.

\section{General methods}

\section{Subjects}

Eighty-seven 4-day-old Wistar rats were used. The animals, male and female, were derived from 18 dams, mated at the vivarium of Instituto de Investigaciones Médicas Dr. Alfredo Lanari (IDIM-CONICET, Argentina) and given ad libitum access to water and lab chow (Cooperación, Buenos Aires, Argentina). The litter representation and number of subjects in each experiment were as follows: Experiment $1-24$ animals derived from six litters, 12 animals in each group; Experiment 2-63 animals, 12 litters. The day of parturition was considered PD 0 and, within each litter, only one male or female was assigned to a given treatment condition (Holson \& Pearce, 1992). The vivarium had a 12-h/12-h light/dark cycle, with lights on at 7:00 am, and controlled temperature $\left(22^{\circ} \mathrm{C}\right)$ and humidity. Rats used in these experiments were maintained and treated in accordance with the Guide for the Care and Use 
of Laboratory Animals by the National Research Council (1996). The experimental protocol (N 010-14) was approved by the institutional animal care committee (CICUAL).

\section{Apparatus}

Surrogate nipple The surrogate nipple was cast from rubber latex (AMACO rubber latex, Indianapolis, IN, USA) and molded into a conical form to measure $12 \mathrm{~mm}$ long with a rounded tip measuring $1 \mathrm{~mm}$ in diameter and the base measuring $2.5 \mathrm{~mm}$ in diameter. The base of the surrogate nipple was attached to the end of an angled dental probe to facilitate presentation by the experimenter (Petrov, Varlinskaya, \& Smotherman, 1997). Polyethylene tubing (Clay Adams, Sparks, MD, USA) run throughout the length of the nipple. The tubing was attached to a syringe, which was filled with the corresponding solutions. The nipple was in continuous contact with the mouth of the animal, which was gently stimulated on the lips with the tip of the device. The pressing of the nipple by the pup's mouth was associated with a negative pressure that in turn allowed voluntary intake. The pup was clamped in a semi-supine posture into a "vest" fashioned out of ultra-thin, elastic rubber. This light restraint prevented righting attempts but did not otherwise produce discomfort nor hinder the pup's movements.

\section{Solution}

The nipple delivered a mixture of quinine and sucrose, which has been shown to emulate the taste of alcohol (Di Lorenzo et al., 1986). Following previous studies (Arias \& Chotro, 2005a; Diaz-Cenzano \& Chotro, 2010; López \& Molina, 1999), this solution was prepared by diluting sucrose $0.1 \mathrm{M}$ + quinine $0.0001 \mathrm{M}$ (Sigma-Aldrich, Buenos Aires, Argentina) with distilled water.

\section{Procedure}

\section{Experiment 1: Testing responsiveness to a surrogate nipple providing a solution that emulates the taste of alcohol (i.e., sucrose and quinine) in the presence of the mother's odor}

We explored the effects of the mother's odor on attachment to an artificial nipple delivering a solution that mimics the taste of alcohol. Two groups were stimulated for $6 \mathrm{~min}$ with the artificial nipple providing this sweet and bitter solution in the presence (Odor Group) or absence (No odor Group) of the dam. The test involved delivery of the quinine-sucrose solution via the artificial nipple in the presence (Odor Group, the anesthetized dam was about $2 \mathrm{~cm}$ away from the nose of the pup) or absence (No-odor Group) of the mother's odor.
Experiment 2: Responsiveness toward a surrogate nipple providing sucrose-quinine or water in the presence of the own mother's or another mother's odor

In Experiment 1 the experimental, but not the control, pups were exposed to the odor provided by an anesthetized mother. There was no physical contact between the pups and the dam, yet the pups were exposed to the social stimulus and to the heat provided by the dam. It was not clear, then, if the odor was the only factor inducing differential responsiveness to the nipple. Experiment 2 controlled these confounding factors by assessing responsiveness to the nipple in the presence of the anesthetized mother or in the presence of another, unrelated, anesthetized dam. Moreover, to assess the specificity of the promoting effect of the dam on nipple attachment, a sub-group of pups was offered water, instead of the sucrose-quinine mixture, through the nipple. A 2 (female present during the test: own mother or another mother) $\times 2$ (solution given via the nipple) factorial design was employed in Experiment 2. Each of the four groups had 15-16 animals. The dams (related and unrelated) were at the same postpartum day.

In both Experiments, the test was performed between 9 a.m. and noon. At DP 4, the dam was anesthetized with a mix of ketamine $(40 \mathrm{mg} / \mathrm{kg})$ and xylazine $(5 \mathrm{mg} / \mathrm{kg})$. The pups were then placed into a heating chamber (kept at $35^{\circ} \mathrm{C}$; Simen, Buenos Aires, Argentina) and, 15 min later, gently stimulated in the urogenital region with cotton to induce urination and defecation. Each animal was weighed, equipped with the vest, and attached to a tempered mirror. The experimenter stimulated the perioral area of the pup with the tip of the surrogate nipple. The oral grasp response, which allowed suckling and hence access to the solution, involved an active movement of the pup's head toward the surrogate nipple, which resulted in the tip of the nipple entering the oral cavity and the mouth closing around it. From this response the following measures were obtained: latency to grasp, total time spent on the nipple (sum of the duration of all grasps), frequency of grasps (attachments initiated), and mean duration of an individual grasp response (total time of grasps/ number of grasps). The consumption of the solution was measured via the percentage of bodyweight gain: [(post-testing weight - pre-testing weight)/pre-testing weight $* 100]$.

All experiments were videotaped and subsequently analyzed by two observers (observer's reliability $>85 \%$ ) who were blind to the experimental conditions.

\section{Data analysis}

In Experiment 1 each variable was analyzed using a t-test for independent samples. The grouping factor was the odor condition during the test (mother's odor or no-odor exposure). Between-group analyses of variance (ANOVAs) were employed in Experiment 2. Odor condition (own mother's odor or other mother's odor) and Solution (sucrose-quinine or water) were the independent factors. Significant interactions were further 
analyzed by Tukey's HSD post hoc comparisons, and planned comparisons were used when justified by a priori hypotheses. Data were collapsed across sex since, across variables, this factor exerted no significant main effect nor interacted with the remaining variables. The alpha level was set at $\leq 0.05$.

\section{Results}

\section{Experiment 1}

Figure 1 shows latency to grasp the nipple, number of grasps, total time of grasps, mean of grasp duration, and percentage of bodyweight gain during the test. It seems that the presence of the mother significantly facilitated approach and contact with the nipple. The statistical analysis supported these observations. Subjects evaluated in the presence of the mother showed, when compared to animals in the no-odor group, significantly greater total time attached to the nipple, $t_{22}=4.81, p<.00008$, number of grasps, $t_{22}=4.14, p<.0004$, mean duration of grasps, $t_{22}=3.02$, $p<.01$, and a significantly lower latency to grasp the nipple, $t_{22}=$ $-5.71, p<.00004$. Percentage of bodyweight gained was greater in the odor versus the no-odor group, but this difference did not reach statistical significance $(p>.05)$.

\section{Experiment 2}

Figure 2 illustrates the behaviors measured in Experiment 2. The ANOVA for percentage of bodyweight gain revealed a significant interaction between odor condition and solution, $\mathrm{F}_{1}$, ${ }_{59}=7.60, \mathrm{p}<.01$. The post hoc tests revealed significantly greater intake of sucrose-quinine than water in those pups stimulated with the odor of the mother. On the other hand, the post hoc tests indicated that pups stimulated with the odor of an unrelated dam consumed as much sucrose-quinine as water. Also of importance, intake of sucrose-quinine was significantly greater in the presence of the related dam than in the presence of the non-related dam.
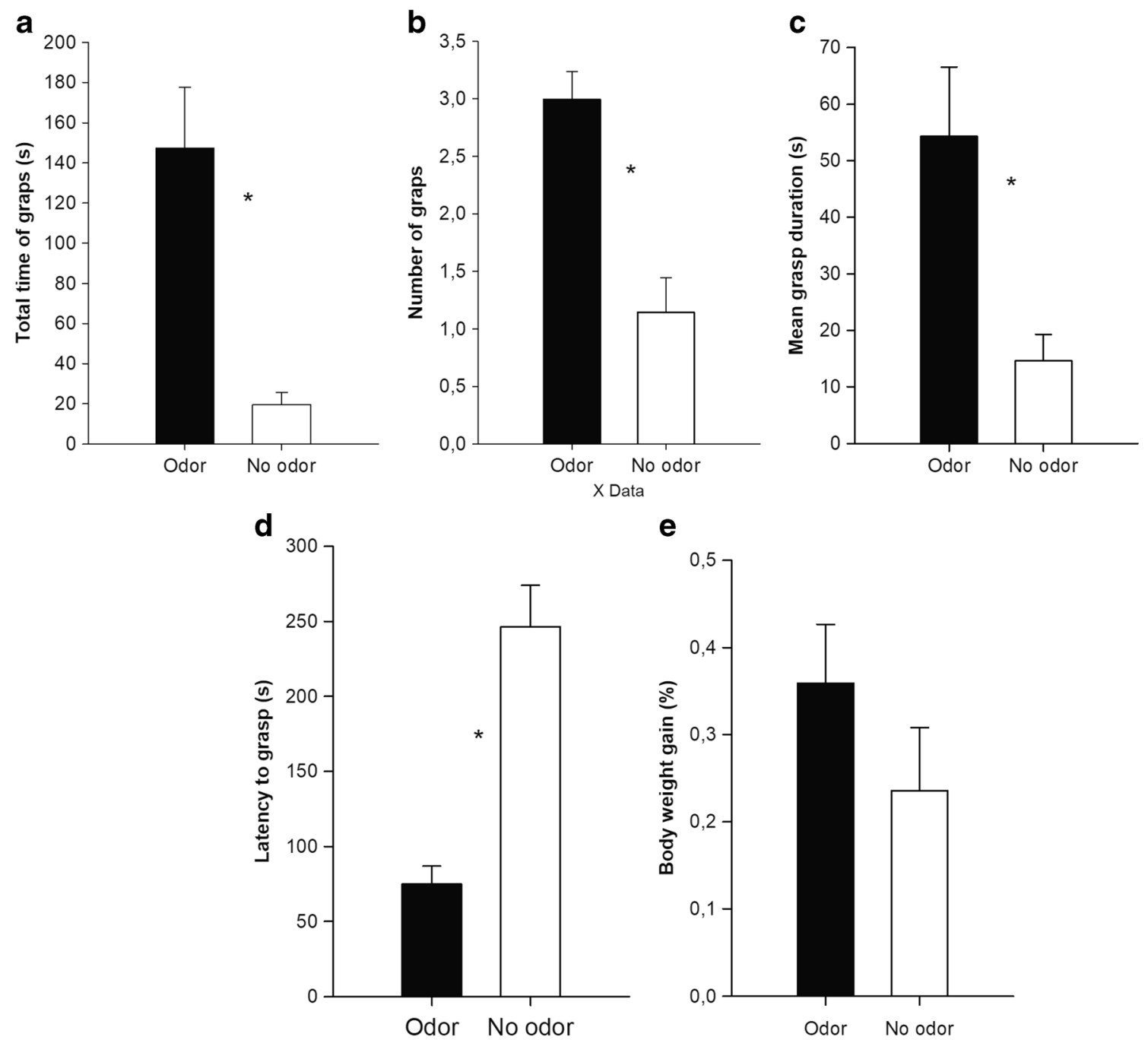

Fig. 1 Mean $( \pm$ SE) of (a) total time grasp, (b) mean grasp duration, (c) number of grasps, (d) latency to grasp, and (e) percentage of body weight gained, during the 6-min presentation of the artificial nipple containing quinine and sucrose solution. *Indicates $p$ values $<.05$ 

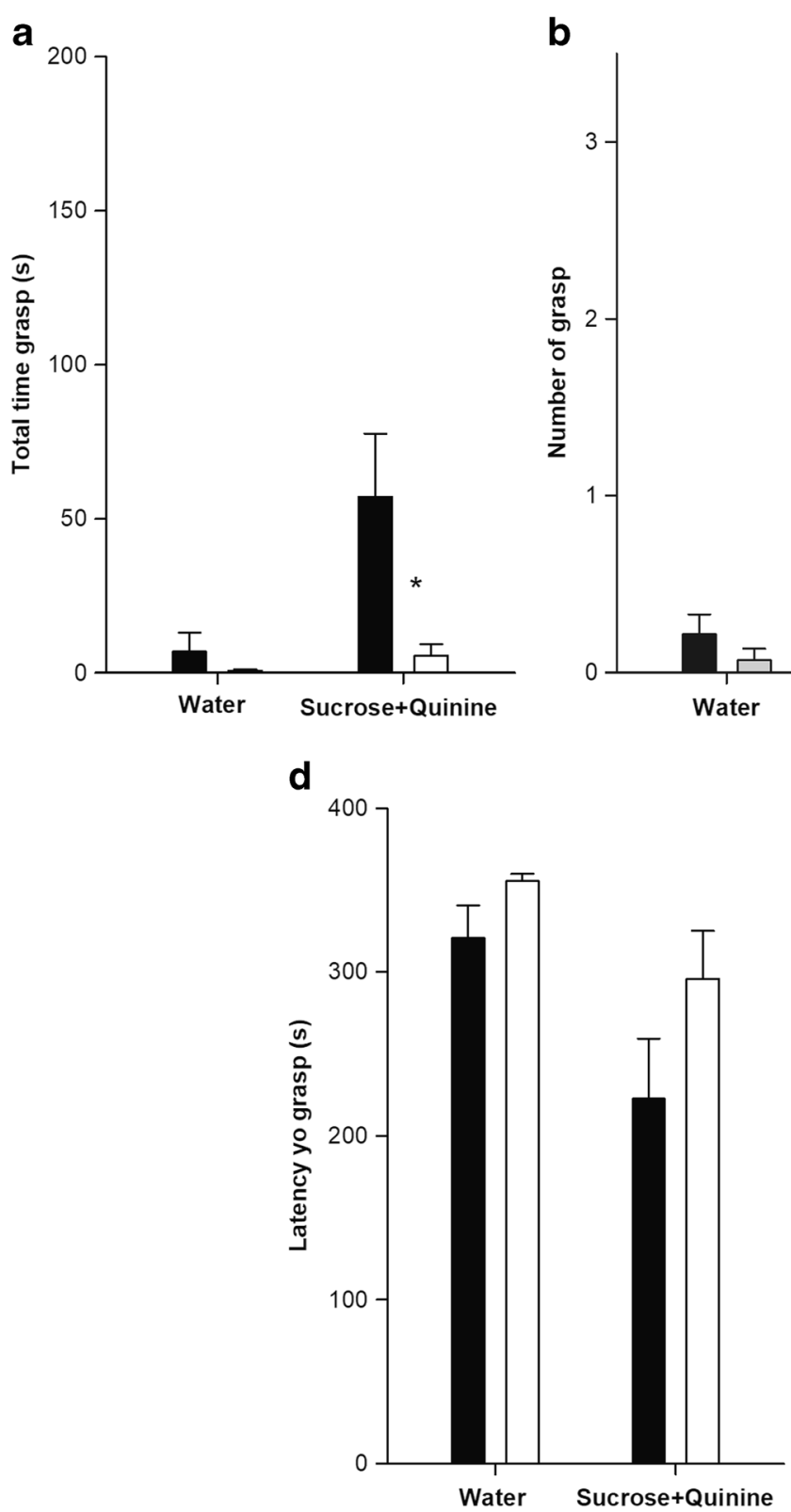

Fig. 2 Mean $( \pm$ SE) of (a) total time grasp, (b) mean grasp duration, (c) number of grasps, (d) latency to grasp, and (e) percentage of body weight gained, during the 6-min presentation of the artificial nipple containing

The ANOVAs for total time spent grasping the nipple and mean grasp duration indicated a lack of significant main effects or significant interactions. Figure 2 suggests, however, an exacerbated response in the group given sucrose-quinine compared with the other groups. Guided by these impressions, and by our $a$ priori hypotheses, we conducted planned comparisons and observed significantly greater time spent on the nipple $\left(F_{1,31}=4.06\right.$, $p<.05)$ and mean grasp duration $\left(F_{1,31}=4.14, p<.05\right)$ in the group that received the sucrose+quinine solution in the presence of their own mother than in the group assessed in the presence of another mother. Number of grasps and latency to grasp were not affected by the factors under analysis $(p>.05)$.
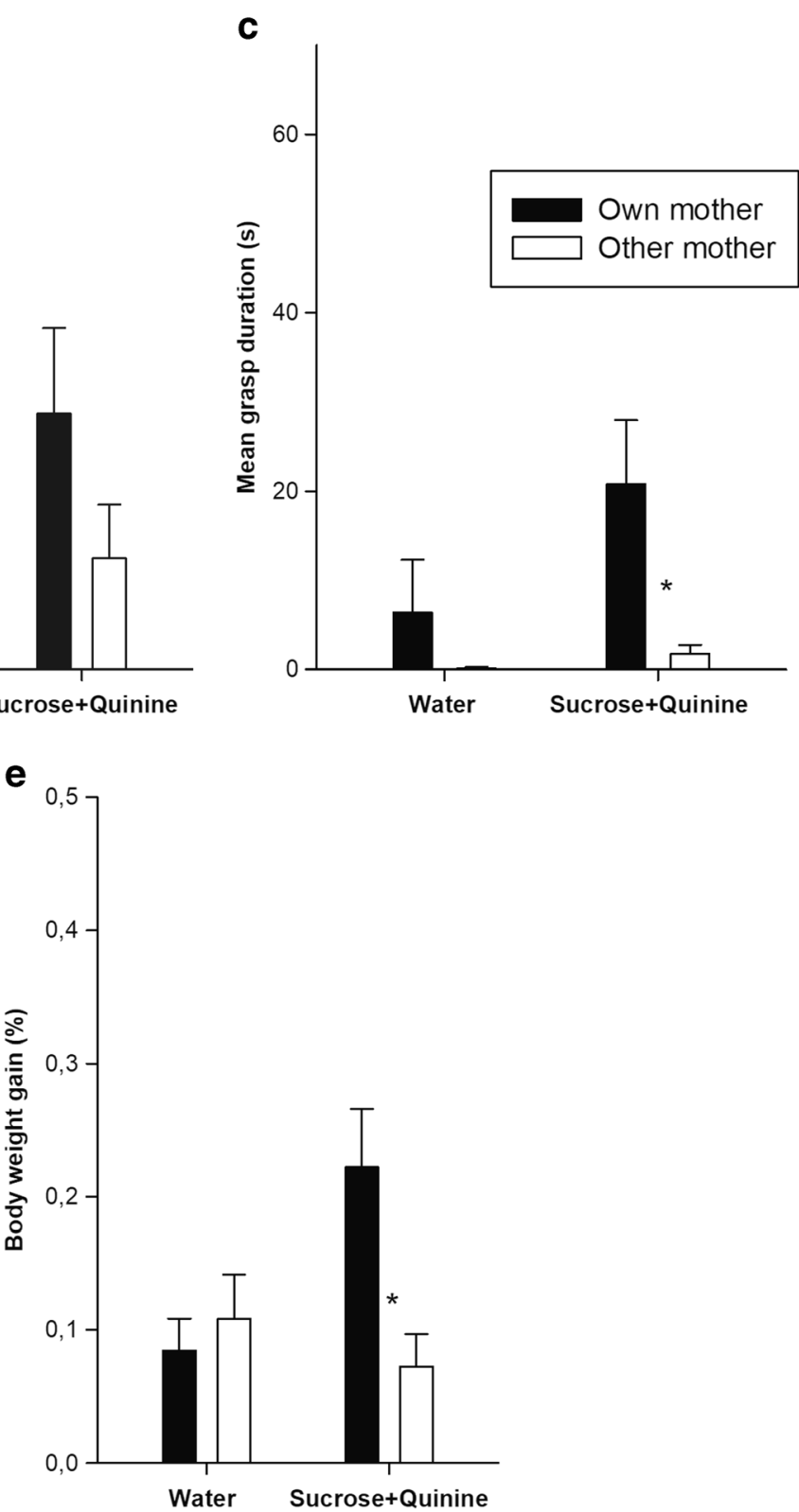

water (left bars) or quinine and sucrose solution (right bars). *Indicates $p$ values $<.05$

\section{Discussion}

Studies have shown that early on neutral odors (e.g., cineole) elicited alcohol intake in rat pups following pairings with ethanol (Abate, Spear, \& Molina, 2001; March, Abate, \& Molina, 2009). The most important new information gained from the present study is that 4-day-old rats tested in the presence of the mother (and hence exposed to maternal odor cues previously experienced in utero) exhibited enhanced seeking and intake of a solution that mimics the chemosensory, but not the post-absorptive, properties of ethanol. This suggests that, during the neonatal period, the mere presence of familiar odors may facilitate 
acceptance of flavors with aversive components (i.e., bitter taste), and therefore may act as a permissive factor for ethanol seeking and intake.

In Experiment 1, the experimental group had access to a heat source and social contact via the anesthetized dam. Experiment 2 included control animals stimulated with the odor provided by an anesthetized, yet unrelated, dam, and thus dispelled the alternative explanations for these issues. The animals assessed in the presence of their mother exhibited a greater percentage of bodyweight gain and performed significantly more responses toward the artificial nipple than those assessed in the presence of an unrelated dam. This difference was not observed when the artificial nipple dispensed water, suggesting that the promoting effect of pre-exposed odors upon fluid seeking and intake is expressed only when the solutions have an aversive component. These results replicate studies in newborn rats (Kamenetzky et al., 2015) that reported greater intake and grasp responses to an artificial nipple (scented with a pre-exposed lemon odor) that dispensed a moderate concentration of quinine, but not to a nipple providing sucrose. The present study generalizes this phenomenon to a biologically relevant odor (i.e., mother's odor), and to a solution that emulates the taste of a drug of abuse (ethanol) that can be readily transferred to breast milk after maternal intoxication.

The taste of milk can be altered by the diet ingested by the mother. It has yet to be assessed how the tastes experimented with in the maternal milk could interact with previously learned odors that are present in the suckling context. Studies with human babies, however, showed that when mothers consume a capsule of garlic, babies display greater response towards the breast (Mennella \& Beauchamp, 1991b; Mennella \& Beauchamp, 1993b). In addition, babies who were exposed to milk containing alcohol consumed more of the breast milk compared to babies exposed to uncontaminated milk (Mennella, 1999; Mennella \& Beauchamp, 1991a). In light of these results, it is interesting to hypothesize that odors present in the context of breastfeeding could modulate responses to the maternal breast when the following two conditions are met: (1) a familiar odor is present and (2) a substance with a bitter taste is offered.

Several pre-clinical (Fabio et al., 2013; Molina, Spear, Spear, Mennella, \& Lewis, 2007) and epidemiological (Dawson et al., 2008; Jenkins et al., 2011; Windle \& Windle, 2012) studies indicate that early exposure to ethanol increases subsequent acceptance of this drug. These studies have analyzed several factors that can modulate the effect of early-onset ethanol use upon subsequent ethanol abuse and dependence (e.g., dose of first ethanol exposure). Yet, little attention has been devoted to date to the interaction of the taste of the drug with other, familiar or non-familiar, odors in combination with ethanol access. The results of the present study show that a biologically relevant pre-exposed odor, the scent of the own mother, enhanced the acceptance of the sucrose-quinine mixture. The sweet component of ethanol has been traditionally thought to induce or facilitate alcohol consumption, yet the data from this research and those obtained by Kamenetzky et al. (2015) suggest that the bitter component could also play an important role, particularly early in life in the context of breastfeeding. This is a preliminary hypothesis that requires more evidence to be confirmed.

It has been shown that experimental contamination of amniotic fluid with alcohol increases later, postnatal, consumption and palatability of that substance (Arias \& Chotro, 2005a, 2005b). It can be proposed that, in those experiments, the animals went through the two stages of our protocol. In phase 1, the animals were naturally pre-exposed to the mother's odor during the last stage of gestation. In phase 2, in turn, the animals were exposed to ethanol through amniotic fluid that also provided exposure to the mother's odor. When tested postnatally, these pups exhibit, akin to those in the present report, greater acceptance of alcohol or alcohol-related cues. A large body of evidence shows that both human (Mennella, Jagnow, \& Beauchamp, 2001) and rat (Abate, Pueta, Spear, \& Molina, 2007; Chotro \& Arias, 2006) fetuses are capable of perceiving odors present in the amniotic fluid during the last stage of gestation. The present results suggest that the intake of amniotic fluid contaminated with alcohol is enhanced in these subjects, due to the interaction of the bitter taste and maternal odor.

In summary, our results indicated that the presence of maternal odor significantly enhanced attachment to, and intake from, an artificial nipple dispensing a solution that emulated the taste of alcohol. It is noteworthy that the sucrose-quinine mix employed was novel, which indicates that these results cannot be the consequence of previously learned associations involving such taste.

This study contributes to the little explored area of the interaction between olfaction and taste during early ontogeny. The results are consistent with previous work from our laboratory in which 3- or 12-day-old rats exhibited an increase in the consumption of a bitter solution when tested in the presence of their own mother, but not when tested in the presence of another, unrelated, dam (Ifran, Suárez, Pautassi, \& Kamenetzky, 2018). It seems that these early experiences are key for the development of eating habits or the consumption of psychoactive substances. The animal model outlined in the present study should be useful for assessing strategies aimed at solving problems related to the early rejection or acceptance of unpalatable substances, including those subjected to abuse.

Funding This work was supported by the PIP-CONICET-2012 [grant number 11220110100228], BID-PICT 2014 [grant number 3212] and the Universidad Abierta Interamericana, awarded to Giselle Kamenetzky.

\section{References}

Abate, P., Spear, N. E. \& Molina, J. C. (2001). Fetal and Infantile Alcohol-Mediated Associative Learning in the Rat. Alcoholism: Clinical and Experimental Research, 25(7):989-998 
Abate, P., Pueta, M., Spear, N. E. \& Molina, J. C. (2007). Fetal learning about ethanol and later ethanol responsiveness: Evidence against "safe" amounts of prenatal exposure. Experimental Biology and Medicine, 233, 139-154.

Arias, C. \& Chotro, M. G. (2005a). Increased preference for ethanol in the infant rat after prenatal ethanol exposure, expressed on intake and taste reactivity tests. Alcoholism: Clinical and Experimental Research, 29, 337-346.

Arias, C. \& Chotro, M. G. (2005b). Increased palatability of ethanol after prenatal ethanol exposure is mediated by the opioid system. Pharmacology, Biochemistry and Behavior, 434 - 442.

Bachmanov, A. A., Kiefer, S. W. Molina, J. C., Tordoff, M. G., Duffy, V. B., Bartoshuk, L. M. \& Mennella, J. A. (2003). Chemosensory factors influencing alcohol perception, preferences, and consumption. Alcoholism: Clinical and Experimental Research, 27, 220-231.

Bannoura, M. D., Kraebel, K. S., Spear, L. P. \& Spear, N. E. (1998). Effects of preweanling ethanol odor exposure on ethanol preference. Alcohol, 15, 213-217.

Beauchamp, G. K. \& Mennella, A. (2011). Flavor perception in human infants: development and functional significance. Digestion, 83, $1-6$.

Berridge, K. C. (2000). Measuring hedonic impact in animals and infants: Microstructure of affective taste reactivity patterns. Neuroscience and Biobehavioral Reviews, 24, 173-198.

Chotro, M. G. \& Arias, C. (2006). Exposure to low and moderate doses of alcohol on late gestation modifies infantile response to and preference for alcohol in rats. Annali dell Istituto Superiore di Sanita, 42, 22-30.

Dawson, D. A., Goldstein, R. B, Chou, S.P., Ruan, W. J \& Grant B. F. (2008). Age at first drink and the first incidence of adult-onset DSMIV alcohol use disorders. Alcoholism: Clinical and Experimental Research, 32, 2149-2160.

Di Lorenzo, P. M., Kiefer, S. W., Rice, A. G. \& Garcia, J. (1986). Neural and behavioral responsivity to ethyl alcohol as a tastant. Alcohol, 3, 55-61.

Diaz-Cenzano, E. \& Chotro, M.G. (2010). The effect of taste familiarity on intake and taste reactivity in infant rats. Developmental Psychobiology, 52, 109-120.

Fabio, M. C., March, S. M., Molina, J. C., Nizhnikov, M. E., Spear, N. E. \& Pautassi, R. M. (2013). Prenatal ethanol exposure increases ethanol intake and reduces $\mathrm{C}$-fos expression in infralimbic cortex of adolescent rats. Pharmacology Biochemistry and Behavior, 103, 842-852.

Ganchrow, J. R., Steiner, J. E. \& Canetto, S. (1986). Behavioral displays to gustatory stimuli in newborn rat pups. Developmental Psychobiology, 19, 163-174.

Holson, R. R., Pearce, B. (1992). Principles and pitfalls in the analysis of prenatal treatment effects in multiparous species. Neurotoxicology and Teratology 14, 221-8.

Ifran, M. C., Suárez A, Pautassi, R. M. \& Kamenetzky, G. V. (2018). Maternal odor exposure modulates acceptance of a bitter taste in newborn and infant rats. Frontiers in Psychology doi: https://doi. org/10.3389/fpsyg.2018.01327

Jenkins, M. B., Agrawal, A., Lynskey, M. T., Nelson, E. C., Madden, P. A, Bucholz, K. K. \& Heath, A. C. (2011). Correlates of alcohol abuse/dependence in early-onset alcohol-using women. The American Journal on Addictions, 20, 429-434.

Kamenetzky, G. V., Suárez, A., Pautassi, R., Mustaca, A., \& Niznikov, M. (2015). Effect of pre-exposure to odors on the first intake behavior. Physiology and Behavior. Special Issue, 148, 51-57.

Kamenetzky, G. V., Suárez, A. B.; Ifran, M. C., Nizhnikov, M. E. \& Pautassi, R. M. (2018). Influence of prenatal pre-exposure to an odor on intake behavior of an aversive solution in newborn rats. Neuroscience Letters, 673, 7 - 11 .

Kiefer, S. W., Bice, P. J., Orr, M. R. \& Dopp, J. M. (1990). Similarity of taste reactivity responses to alcohol and sucrose mixtures in rats. Alcohol, 7, 115-120.

Kiefer S. W. \& Lawrence, G. J. (1988). The sweet - bitter taste of alcohol: aversion generalization to various sweet - quinine mixtures in the rat. Chemical Senses, 13, 633-641.
Landers, M. S. \& Sullivan, R. M. (2012). The development and neurobiology of infant attachment and fear. Developmental Neuroscience, $34,101-114$

López, M. F. \& Molina J. C. (1999). Chronic alcohol administration in the rat pup: effects upon later consumption of alcohol and other palatable solutions. Addiction Biology, 4, 169-179.

March, S. M., Abate, P., Spear, N. E. \& Molina, J. C. (2009). Fetal exposure to moderate ethanol doses: heightened operant responsiveness elicited by ethanol-related reinforcers. Alcoholism: Clinical and Experimental Research, 33, 1981-1993.

Mennella, J. A. (1999). The transfer of alcohol to human milk: Sensory implications and effects on mother-infant interaction In: N. E. Spear, L. P. Spear, J. H. Hanningan \& C. Goodlett (Eds.). Alcohol and alcoholism: Brain and development. Lawrence Erlbaum Associates, Mahwah, 177-198.

Mennella, J. A. \& Beauchamp, G. K. (1991a). The transfer of alcohol to human milk: effects on flavor and the infant's behavior. The New England Journal of Medicine, 325, 981-985.

Mennella, J. A. \& Beauchamp, G. K. (1991b). The transfer of alcohol to human milk: effects on flavor and the infant's behavior. The New England Journal of Medicine, 325, 981-985.

Mennella, J. A. \& Beauchamp, G. K. (1993a). Beer, breast feeding and folklore. Developmental Psychobiology, 26, 459-466.

Mennella, J. A. \& Beauchamp, G. K. (1993b). The effects of repeated exposure to garlic-flavored milk on the nursling's behavior. Pediatric Research, 34, 805-808.

Mennella, J. A. \& Beauchamp, G. K. (1996). Developmental changes in the acceptance of protein hydrolysate formula. Developmental and Behavioral Pediatrics, 17, 386-391.

Mennella, J. A. \& Gerrish, C. J. (1998). Effects of exposure to alcohol in mother's milk on infant sleep. Pediatrics, 101(5), e2-e2

Mennella, J. A., Jagnow, C. P. \& Beauchamp, G. K. (2001). Prenatal and postnatal flavor learning by human infants. Pediatrics, 107, 88-94.

Miller, S. \& Spear, N. E. (2008). Olfactory learning in the rat neonate soon after birth. Developmental Psychobiology, 50(6):554-565

Miller, S. \& Spear, N. S. (2009). Olfactory learning in the rat immediately after birth: Unique salience of first odors. Developmental Psychobiology, 51(6):488-504

Miller, S. \& Norman, E. (2010). Mere odor exposure learning in the rat neonate immediately after birth and one day later. Developmental Psychobiology, 52, 343-351.

Molina, J. C., Spear, N. E., Spear, L. P., Mennella, J. A. \& Lewis, M. J. (2007). The International Society for Developmental Psychobiology $39^{\text {th }}$ Annual Meeting Symosium: Alcohol and development: Beyond fetal alcohol syndrome. Developmental Psychobiology, 49, 227-242.

Moriceau, S., Roth, T. L., Okotoghaide, T. \& Sullivan, R. M. (2004). Corticosterone controls the developmental emergence of fear and amygdala function to predator odors in infant rat pups. International Journal of Developmental Neuroscience, 22, 415-42.

Moriceau, S. \& Sullivan, R.M. (2005). Neurobiology of infant attachment. Developmental Psychobiology, 47, 230 - 242.

National Research Council. (1996). Guide for the care and use of laboratory animals. Washington, DC: National Academic Press.

Nizhnikov, M. E., Petrov, E. S., Varlinskaya, E. I. \& Spear, N. E. (2002). Newborn rats' first suckling experience: Taste differentiation and suckling plasticity. Physiology \& Behavior, 76, $181-198$.

Pedersen P. E., Williams C. L., Blass E. M. (1982). Activation and odor conditioning of suckling behavior in 3-day-old albino rats. Journal of Experimental Psychology: Animal Behavior Processes, 8, 329-341.

Petrov, E. S., Nizhnikov, M. E., Kozlov, A. P., Varlinskaya, E. I., Kramskaya, T. A. \& Spear, N. E. (2004). Repetitive exposures to a surrogate nipple providing nutritive and non-nutritive fluids: Effects on suckling behavior of the newborn rat. Appetite, 43. 185-94.

Petrov, E. S., Varlinskaya, E. I. \& Smotherman, W. P. (1997). The newborn rat ingests fluids through a surrogate nipple: A new technique 
for the study of early suckling behavior. Physiology \& Behavior, 62, $1155-1158$

Upton, K. J. \& Sullivan, M. R. (2010). Defining age limits of the sensitive period for attachment learning in rat pups. Developmental Psychobiology, 52, 453-464.

Windle, M. \& Windle, R. C. (2012). Early onset problem behaviors and alcohol, tobacco, and other substance use disorders in young adulthood. Drug and Alcohol Dependence, 121, 152-158.
Zeanah, C. H. Boris, N. W. \& Larrieu, J. A. (1997). Infant development and developmental risk: A review of the past 10 years. Journal of the American Academy of Child \& Adolescent Psychiatry, 36, 65-178.

Publisher's note Springer Nature remains neutral with regard to jurisdictional claims in published maps and institutional affiliations. 